КУЛЬТУРОЛОГИЯ

DOI: 10.17805/trudy.2016.5.9

\title{
СЕРЕБРЯНЫЙ ВЕК И РУССКОЕ КИНО ЭПОХИ АВАНГАРДА
}

\author{
Л. В. Попова \\ (Московский гуманитарный университет)
}

Аннотация: В статье исследуется русский кинематограф как наследие культуры Серебряного века, как сочетание «духа пластики» и «духа музыки», аполлонического и дионисийского.

Ключевые слова: С. М. Эйзенштейн; П. А. Флоренский; Л. В. Кулешов; В. Б. Шкловский; Б. М. Эйхенбаум; Серебряный век; русское кино; история кино

\section{THE 'SILVER AGE' OF RUSSIAN CULTURE AND RUSSIAN AVANT-GARDE CINEMA}

\author{
L. V. Popova \\ (Moscow University for the Humanities)
}

Abstract: The article studies the Russian cinema as a piece of cultural heritage from the 'silver age' of Russian culture, as a combination of the «spirit of plasticity» and «spirit of music», of the Apollonian and the Dionysian.

Keywords: S. M. Eisenstein; P. A. Florensky; L.V. Kuleshov; V. B. Shklovsky; B. M. Eikhenbaum; Russian cinema; history of cinema

Эпоха рубежа XIX-XX веков сложная и неоднозначная, ее считают эпохой эстетизма и декаданса в Западной Европе и Серебряного века в России. Декаданс принято считать синонимом упадка. С другой стороны, он явился некой эстетической революцией. Искусство получило полную автономию, с него были сняты все ограничения. Воспевалось и «светлое», и «темное». Искусство оказалось в ситуации безграничного выбора. Но в этом-то и таилась опасность, так как возрастала ответственность творческого деятеля за свое творчество. Главным властителем дум был Ф. Ницше, который определил творческого деятеля как человека, который «сам завоёвывает себе свою культуру и принуждает богов вступить с ним в союз, ибо в своей самоприобретенной мудрости он держит в руке их существование и пределы» (Ницше, 1990: 90). Свои эстетические взгля- 
ды Ницше выразил в трактате «Рождение трагедии из духа музыки». Искусство, в представлении Ницше, это синтез двух противоборствующих начал: аполлонического и дионисийского. Аполлон - бог пластических образов, он олицетворяет форму, меру, гармонию. Дионис - связан с непластическим искусством - искусством музыки (Попова, 2013).

Кинематограф превратил фотографию, искусство, останавливающее момент, мгновение, в «образ-движение», как определил его Ж. Делез (Делез, 2013). По его мнению, в кино «визуальный образ исходит от Аполлона» (там же: 505), музыкальный - образ «дионисийский» (там же).

Кинематограф явился своего рода ответом на вызовы эпохи, которая представляла собой сгусток противоречий - социально-политических, религиозно-мистических, этических и эстетических. Эпоха начала XX века, по мнению Н. Бердяева, самая «невоплощенная и незаконченная» в ней «дух музыки господствует над духом пластики» (Бердяев, 1994: 238). Выход из кризиса Бердяев видел лишь в теургическом искусстве. Но оно осталось прекрасной мечтой. Из символистов ближе всех к идеям теургии оказался Н. Рерих с его «Гималайской серией». И все же «дух пластики» и «дух музыки» соединились в новом искусстве - кинематографе. В данном случае, интересна точка зрения Н. А. Хренова, согласно которой ценности элитарной культуры Серебряного века прорываются в массы. При этом вопрос о теургии режиссерами не обсуждался, но кинематографический процесс этого времени свидетельствует, что «теургия развертывалась в формах массового искусства» (Хренов, 2008: 102). «Не будет ошибкой утверждать, - считает Н. Хренов, - что С. Эйзенштейн подхватывает идеи символистов и развивает их применительно к осмыслению природы кино...» там же: 88).

В кризисе оказалось не только искусство, но и искусствознание, как наука. Теория искусств и эстетика не давали ответа на вызовы эпохи. Зарождение «формального метода» явилось некой попыткой выхода из сложившейся ситуации. Эйзенштейн анализировал Пушкина, его «Полтаву», «Медного всадника». Он отмечал, что Пушкин писал монтажно. И не только Пушкин, но и мастера прозы. Так, например, проза Ч. Диккенса оказала влияние на режиссера Д. У. Гриффита (Эйзенштейн, 2002: 9), который стоял у истоков монтажа. В «Оливере Твисте», по мнению Эйзенштейна можно найти типичный для Гриффита монтажный метод «монтажного введения параллельных сцен, врезанных друг в друга» (там же: 34).

Гриффит изобрел параллельный монтаж. В картине «Нетерпимость» (1916) он одновременно рассказал четыре истории, объединенные общей идеей «Мать и закон», «Жизнь и страдания Христа», «Падение Вавилона», «Варфоломеевская ночь». Но прием параллельного монтажа встречается и в более ранних работах Гриффита «Много лет спустя» (1908), экраниза- 
ция «Эноха Ардена» А. Теннисона, а также в «Юдифи из Бетулии» (1914). Основы монтажа, указывает С. Эйзенштейн, были заложены американской культурой, но, «окончательное осмысление и мировое признание которому принесло наше кино» (там же: 19).

Воспитанный на американских фильмах Л. В. Кулешов обнаружил следующую закономерность: американские картины состоят из мелких сцен, склеенных в определенной последовательности, в то время как русские картины состоят из длинных кусков. Ритмическое построение американских картин во многом определилось под влиянием темпа американской жизни, коммерческому складу американского кино (Кулешов, 1987а: 166). В результате стало известно, что средство воздействия на зрителя лежит в «системе чередования кусков, составляющих кинокартину» (там же: 167). Короткий монтаж был тогда назван «американским монтажом», длинный - «русским» (там же). Это не означает, что американские фильмы были более глубокие, но они были более организованные, прежде всего, сочетанием кадров между собой. По мнению Кулешова, в них было более четкое изображение, более тщательный подбор актеров.

В 1922 г. Л. В. Кулешов открыл явление, которое вошло в историю как «эффект Кулешова». Был снят крупный план актера Ивана Мозжухина и несколько общих планов: тарелка с супом, ребенок в гробу и девушка. План с Мозжухиным разрезали на три части и соединили с другими кадрами. При соединении с тарелкой супа, лицо актера выражало голод, с мертвым ребенком - скорбь, с девушкой - влюбленность. В результате соединения кадров, то есть монтажа, рождался новый смысл. Следующей находкой Кулешова стал «географический эксперимент». Кулешов развил принцип параллельного монтажа Гриффита. Действие может происходить одновременно в Америке, Европе и России. Все вышеуказанные принципы Кулешов применил еще в 1918 г. в картине «Проект инженера Прайта». Действующие лица, отец и дочь, должны были идти по полю и видеть ферму. Но пришлось ферму снять в одном месте, а идущих по лугу отца с дочерью - в другом. В результате соединения кадров получилось то, что и было задумано. Через несколько лет родился «географический эксперимент», который был осуществлен с помощью актеров А. Хохловой и Л. Оболенского. Хохлова шла в Москве по Петровке, проходила мимо магазина «Мосторг», Оболенский - по набережной Москвы-реки на расстоянии трех верст. Встреча снималась на Пречистенском бульваре, который находился совершенно в другой части города. Встреча и рукопожатие происходит у памятника Гоголю, затем они поворачиваются и смотрят на Белый дом в Вашингтоне. «Географический эксперимент» явился неким синтезом параллельного монтажа и «эффекта Кулешова». Будучи и практиком, и теоретиком, Кулешов выявил некоторую закономерность: кадры 
следует монтировать по определенному принципу: либо по движению, либо по местоположению в кадре (Кулешов, 1987b: 238). Картина имеет в своей основе два ритма: «ритм монтажный и ритм внутрикадровый» (там же: 244). Ритм Кулешов определяет как «закономерное чередование соизмеримых единиц во времени» (там же). Происхождение ритма Кулешов связывает с трудовой деятельностью человека. А формы ритмической деятельности - с физиологическими процессами: с дыханием, сердцебиением. Проблемой ритмизации занимается музыка. Поэтому в измерении времени, по мнению Кулешова, мы имеем законы, которые следует черпать из музыки. Монтажное построение фильма надлежит строить по примеру музыкального произведения: с чередованием сильных и слабых кусков. Сильным куском может быть либо крупный план, либо более энергичное действие внутри кадра. В споре с А. Н. Андриевским, который утверждал, что звуковой и немой монтаж между собой ничего общего не имеют, Кулешов придерживался иной точки зрения. Он считал, что звуковой материал, как и немой, следует тщательно организовывать. Звуковой монтаж требует «плавных переходов, немой монтаж строится на резких переходах с одного момента на другой» (там же: 235). Кулешов одним их первых понял, что не стоит увлекаться работой «шумовиков» и следует записывать «живой звук». Также, Кулешов использовал понятие «кинематографического времени», которое включает в себя «звук и изображение по линии монтажа» (там же: 227). То есть, Кулешов подошел к понятию горизонтального и вертикального монтажа, которое развил впоследствии С. М. Эйзенштейн. Эйзенштейн по-новому понимал форму кинематографического произведения, что роднит его с формалистами.

Формалисты понимали форму «как самое содержание, непрерывно изменяющееся в зависимости от предыдущих образцов» (Эйхенбаум, 1987: 401). Эйзенштейн считал, что форма должна родиться в результате монтажа. Сценарий художественного произведения нужно строить «не на основе каких-то общепринятых драматургических законов, а в изложении содержания приемами, определяющими построения монтажа как такового...» (цит. по: Шкловский, 1973: 103). Этим приемом может быть хроникальная организация материала. Проблемой сюжета в кино среди формалистов наиболее полно занимался В. Б. Шкловский. Анализируя творчество Эйзенштейна, он считал, что попытка переосмысления формы проявилась еще в его спектакле «На всякого мудреца довольно простоты» по А. Островскому, что явилось пародией на Островского. Пародировалась идея «сценарной связанности кусков» (там же: 83), сценическое действие было условным, разбитым на куски, которые назовут потом «аттракционами» (там же). Эйзенштейн, по мнению Шкловского, отрицал сюжет «как интригу» (там же: 98). Дело в том, считал Шкловский, что во все времена сюжет понимали по-разному. B XVIII веке сюжетом назы68 
вали главного актера произведения, чаще всего - первого любовника, в балете - корифея. Члены движения предложили фабулой называть изложение событий, а то, как они изложены автором - сюжетом. Шкловский анализируя сценарий «1905 год», написанный Н. Агаджановой-Шутко и ставшего основой фильма «Броненосец “Потемкин”», констатировал: «Мы видели чудо: сценария нет, но он осуществлен» (там же: 117). Форма, по Шкловскому, рождается из содержания, так как содержание - это «создание художественной структуры для нового понимания» (там же).

Согласно С. Эйзенштейну, кино - столкновение двух методов - «метода изображения и метода образного становления» (Эйзенштейн, 2000: 211). Л. Кулешов выявил горизонтальный и вертикальный виды монтажа. Эйзенштейн ввел эти понятия. Горизонтальный монтаж есть «монтаж в пластической области» (там же: 355), то есть рождается путем соединения кадров между собой. Вертикальный монтаж - внутрикадровый. С этими понятиями Эйзенштейн связывал специфику в кино, в которой «эти элементы в желаемой последовательности и акцентировке (размером во времени - метраж, или размером в пространстве - степень «крупноты») создают в восприятии тот образ явления, ... каким художник хочет заставить видеть свою модель» (там же: 406). Обозначение «вертикальный монтаж», по Эйзенштейну, «вообще уместно для монтажа этапа звукового кино» (там же: 355). Он ввел также понятие «тонфильма»- синтетического зрелища, объединяющего многообразие средств, среди которых: «...игра человека. Игра звуков. Музыки и голосов. Игра объемов. Игра ситуаций. Игра образов и мыслей» (там же: 464). А средство приведения всех этих величин в «партитуру тонфильма - монтаж» (там же).

И все же Эйзенштейн двояко высказывался по поводу звука в кино. Звук в кино был изобретен Ли Де Форестом, а в 1927 г. появились первые звуковые фильмы. В 1928 г. С. Эйзенштейн, В. Пудовкин и Г. Александров выступили с «Заявкой», где оценивали звук как «обоюдоострое изобретение» (там же: 482), но опасность таится в том, что он будет использован «для «высококультурных драм» и прочих «сфотографированных» представлений театрального порядка» (там же: 482-483). Таким образом, звук «будет уничтожать культуру монтажа» (там же: 483). То есть, они предвидели ошибки современных нам кинодеятелей. В то же время, Эйзенштейн предлагал: для того, чтобы этого не случилось, выработать «контрапунктический метод сочетания зрительного и звукового образа» (там же: 488). То есть, «аполлонического» и «дионисийского», «духа пластики» и «духа музыки».

Согласно Эйзенштейну, кинокадр следует рассматривать не как пластическую единицу, а как «монтажный комплекс» (Эйзенштейн, 1964: 393). Неподвижный кадр ничем не отличается от живописного и пред- 
ставляет собой «закрепленный контур» (там же). Подвижный кадр - след движения. Композиционной разницы между ними нет. Разница - в динамике. Примечательно, что П. Флоренского, одного из основоположников учения о теургии, и С. Эйзенштейна волновали одни и те же теоретические вопросы. Согласно П. Флоренскому, композиция есть «форма изображаемого изображения как такового, т. е. способ взаимоотношения и взаимодействия изобразительных средств» (Флоренский, 1993: 128), которые применены в данном произведении. Конструкция, в отличие от композиции, как форма изображаемого произведения, есть «способ взаимоотношения и взаимодействия сил реальности, перелитой помощью произведения, воспринимаемой через него» (там же). То есть, конструкции подчинено не произведение, а «действительность, произведением изображаемая» (там же: 121), композиции - «самое произведение» (там же). Все вышеуказанное Флоренский относит к живописному произведению. С. Эйзенштейн, говоря о композиции отдельного кадра, считал, что искать его «предков» стоит в живописи. Произведения живописи содержат в себе движение, для того, чтобы его передать, нужно разложить неподвижное изображение на отдельные фазы. Художники XI-XIII вв., считал Эйзенштейн, еще не умели схватить динамику. Совершенства в динамике, в передаче движений достигли, по его мнению, О. Домье, еще раньше - Тинторетто, а еще ранее - кумир Эйзенштейна, Леонардо да Винчи. У Домье - Тинторетто «фазы, сцены развертываются между группами действующих лиц, которые по существу, изображают стадии одного и того же акта, одного и того же поступка» (Эйзенштейн, 2000: 394). Классическим примером того же, согласно Эйзенштейну, служит «Путешествие на остров Цитеры» А. Ватто. Примечательно, что аналогичный пример приводит и П. Флоренский: «Все эти пары вполне объединены и сюжетно, и живописно, так что все это движение справа налево представляется сплошным потоком...» (Флоренский, 1993: 248). Кинематографический прием Эйзенштейн находит у Эль Греко. В его «Плане Толедо» он видит кинематографический прием показа архитектурно-пейзажного ансамбля, где все соотношения по высоте «даны в реальности, а не в перспективе» (Эйзенштейн, 2000: 409).

Скульптура, согласно Эйзенштейну, пользуется монтажным приемом еще шире, чем живопись. Так поступает Микеланджело «Анатомическая деформация и гипертрофия форм человеческого тела скрывают под собой тот же прием» (там же: 162). Неспроста Эйзенштейн обращается к исследованиям французского врача-невролога Г. Дюшена, который проводил опыты электрического раздражения отдельных мышц человека и описал это в своем труде «Механизм движения физиономии человека или электрофизиологический анализ выражения страстей» (1876). Дюшен пред- 
ставил голову «исправленного Лаокоона». Оказалось, что в «анатомически возможном» Лаокооне «нет и доли той динамики страдания, которая достигнутая киноприемом, сделала Лаокоона бессметным в веках!» (там же: 163). Античность, по мнению Эйзенштейна, «знала этот метод монтажа, и не только по линии подъема интенсивности выражения страдающего лица» (там же), но и пользовалась тем же приемом «для повышения выразительности характеристики» (там же). Сокращения мышц «Лаокоона» взяты в разные промежутки времени. Этот есть кинематографический прием. По мнению П. Флоренского, скульптура, если и есть подражание внешнему предмету, то - подражание внутренне музыкальное, отвечающее на впечатление предмета ритмическим внутренним взыгранием» (Флоренский, 1993: 84).

В музыке, согласно П. Флоренскому, пространственными характеристиками выступают «темпы, ритмы, акценты, метры..., затем гармония, пользующаяся высотою, гармония и оркестровка, насыщающие пространство элементами сосуществующими...» (там же: 60-61). Флоренский, подобно Эйзенштейну, видит связь музыки с поэзией. Несмотря на коренные различая, все искусства «произрастают от одного корня» (там же: 61). Изобразительное произведение, «есть не более как запись некоторого ритма - образов, и в самой записи даются ключи к чтению ее» (там же: 231). Трехмерный образ дает пространственную форму. Для прочтения художественного произведения необходима еще одна координата - время. Время вводится в художественное произведение «приемом кинематографическим, т. е. расчленением его на отдельные моменты покоя» (там же: 233). И чем глубже изображение по «четвертой координате», т.е. чем заметнее в нем движение, «тем ярче должна выступать анатомическая и физическая противоречивость искаженных образов...» (там же: 258). Моментальная фотография передает не искаженные образы, а реальное положение вещей. Но в этом, согласно П. Флоренскому, и кроется противоречие: «... моментальная фотография движущегося образа не способна передать движения и представляет невыносимое зрелище мгновенно замороженных тел и сказочно спящего замка» (там же: 255). Художественное произведение содержит ряд искажений, но способно передать движение, так как содержит в себе ряд временных промежутков.

«Четвертое измерение?!», - восклицал Эйзенштейн, - «Эйнштейн? Мистика? Пора перестать бояться этой «бяки» четвертого - измерения» (Эйзенштейн, 2000: 507). Эйзенштейн ставит вопрос и о «пятом измерении». И этим измерением является «обертонный монтаж». Для того чтобы разобраться с этим понятием, следует обратиться к исследованию Эйзенштейна касательно видов монтажа по линии кинетического ряда. Эйзенштейн разделяет монтаж на метрический, ритмический, тональный, обе- 
ртонный и, наконец, интеллектуальный, как развитие обертонного.

Метрический монтаж - самый, казалось бы простой, имеющий основным критерием построения повествования «абсолютные длины кусков» (там же: 508), сочетающихся между собой согласно схеме. Но этот вид монтажа - сильное орудие психологического воздействия: «Его четкость приводит в унисон «пульсирование» вещи и «пульсирование» зрительного зала» (там же: 509).

При ритмическом монтаже фактическая длина кадра «не совпадает с математической» (там же). Здесь важен ритм, темп. Ярчайший пример - «одесская лестница» в «Броненосце Потемкина». Сошествие ног солдат переходит в скатывание коляски. «Здесь коляска работает по отношению к ногам как прямой стадиальный ускоритель» (там же: 510).

Тональный монтаж идет по признаку «эмоционального звучания» (там же) куска. Этот кусок, как правило, доминантный. Эйзенштейн выделяет два вида тональности: световую и графическую. Световая тональность связана со степенью «светоколебания». «Светомонтажом», по мнению Эйзенштейна, владел еще Эль Греко. Именно у него появляется «рембрандтовский» свет задолго до рождения Рембрандта, что проявилось в его картинах «Испанская пословица» (вариант 1576-1577 гг.), «Мальчик, задувающий свечу» (1574-1576). Так или иначе, световая тональность связана с игрой света и тени. Графическая тональность дает «резко звучащий кусок»: «Туманы в одесском порту (начало «Траура по Вакулинчуку» в «Потемкине»)» (там же: 511).

Тональный монтаж имеет эмоциональную окраску. Обертонный монтаж есть его продолжение, но он отличается от него «суммарным учетом всех раздражителей от куска» (там же: 513). Обертон в кино сродни обертону в музыке, когда параллельно основному звучанию вступают так называемые «биения»: очень большие турецкие барабаны, колокола, орган. «Это относится к резко выраженным тембровым инструментам с большим превалированием обертонного начала» (там же: 514-515). Обертонный монтаж выводит восприятие из «мелодически эмоциональной окрашенности в непосредственно физиологическую ощущаемость» (там же: 513), то есть воздействует на «психофизиологический» комплекс воспринимающего.

Четыре категории монтажа становятся монтажным построением тогда, «когда они вступают в конфликтные взаимоотношения друг с другом...» (там же). Переход от метрического монтажа к ритмическому есть конфликт «между длиной куска и внутрикадровым движением» (там же: 514). И это очень мощное орудие воздействия на зрителя. Так Эйзенштейн монтирует сцену сенокоса в «Генеральной линии». Отдельные куски взяты «из бока кадра в бок» (там же: 514). Зрители в зале начинали раскачиваться. 
Переход к тональному монтажу есть конфликт между ритмическим началом и тональным. Обертонный монтаж - конфликт между тональным началом и обертонным. Четвертая категория приливом физиологизма повторяет «в высшем разряде категорию первую, снова обретя стадию усиления непосредственной моторики» (там же). Разрешить конфликт обертонов физиологических и обертонов интеллектуальных, считал Эйзенштейн, сможет «интеллектуальное кино» (там же: 516). Оно создаст особую кинематографию, что будет особым вкладом в историю культуры, соединив в себе науку и искусство.

Кино, по Эйзенштейну, - зрелищное искусство. Зритель включается в творческий акт. Достигается это силой монтажа. Индивидуальность зрителя «не только порабощается индивидуальностью автора, но раскрывается до конца в слиянии с авторским смыслом...» (Эйзенштейн, 1964: 171). То есть, образ, который являет нам искусство кино, есть «образ, который задуман и создан автором, но этот образ одновременно создан и собственным актом зрителя» (там же). Н. Бердяев писал, что современное ему искусство лишено катарсиса. Кинематограф явил собой нечто новое, объединившее, подобно греческой трагедии, зрителей всех слоев общества и позволившее им испытать катарсис.

Таким образом, появление такого искусства, как кино, было вполне закономерным. Кинематограф явился неким синтезом «духа пластики» и «духа музыки», сочетанием аполлонического и дионисийского. Кинокадр представляет собой единичный комплекс, сочетание пластической и ритмической составляющий, имеет свою композицию, что роднит его с, одной стороны, с живописью, с другой, наличием ритма и звуков - с музыкальным произведением. В монтаже соединением кадров рождается смысл произведения. Зритель становится соучастником этого рождения.

\section{СПИСОК ЛИТЕРАТУРЫ}

Бердяев, Н. А. (1994) Смысл творчества // Бердяев Н. А. Философия творчества, культуры и искусства : в 2 т. М. : Искусство. Т.1. С. 37-341.

Делез, Ж. (2013) Кино. М. : ООО «Ад Маргинем Пресс». 560 с.

Кулешов, Л. В. (1987а) Искусство кино // Кулешов Л. В. Собрание сочинений : в 3 т. М. : Искусство. Т. 1. Теория. Критика. Педагогика. С. 161-225.

Кулешов, Л. В. (1987b) Практика кинорежиссуры // Кулешов Л. В. Собрание сочинений : в 3 т. М. : Искусство. Т. 1. Теория. Критика. Педагогика. C. 227-342.

Ницше, Ф. (1990) Рождение трагедии, или Эллинство и пессимизм // Ницше Ф. Сочинения : в 2 т. М. : Мысль. Т. 1. С. 47-157.

Попова, Л. В. (2013) Интерпретация «демонического» в философии и эстетике «Серебряного века»// Знание. Понимание. Умение. № 2. С. 
268-272.

Флоренский, П. (1993) Анализ пространственности и времени в художественно-изобразительных произведениях. М. : Издательская группа «Прогресс». 324 с.

Хренов, Н.А. (2008) Образы «Великого разрыва». Кино в контексте смены культурных циклов. М. : Прогресс-Традиция. 536 с.

Шкловский, В. Б. (1973) Эйзенштейн. М. : Искусство. 299 с.

Эйзенштейн, С. М. (2002) Метод. Т. 2 // Эйзенштейн С. М. Гриффит и мы. М. : Музей кино. С. 112-131.

Эйзенштейн, С. М. (1964) Избранные произведения : в 6 т. М. : Искусство. Т. 2.684 с.

Эйзенштейн, С. М. (2000) Монтаж. М. : Музей кино. 592 с.

Эйхенбаум, Б. М. (1987) О литературе. М. : Советский писатель. 544 с.

Попова Лиана Владимировна - кандидат культурологии, преподаватель кафедры философии, культурологии и политологии Московского гуманитарного университета. Адрес: 111395, Россия, г. Москва, ул. Юности, д. 5, корп. 3, к. 423. Тел.: +7 (499) 374-61-81. Эл. адрес: pliana@mail.ru

Popova Liana Vladimirovna, Candidate of Culturology, Lecturer, Department of philosophy, culturology and politology, Moscow University for the Humanities. Postal address: Office 423, 5 Bldg.3 Yunosti St., 111395 Moscow, Russia. Tel.:+7 (499) 374-61-81.E-mail:pliana@mail.ru 